Mirelle Monique de Oliveira Fernandes ${ }^{1}$

Paulo Roberto Alves ${ }^{2}$

William Roberto Dondas ${ }^{3}$

\title{
Marketing e o conceito de ética: principais implicações no ambiente empresarial
}

\section{Resumo}

Dentro da área do marketing, muitas são as indagações sobre a ética no marketing e outros negócios que o envolvem. Mas será que ela realmente está presente neste contexto? A pesquisa buscou responder a esta e outras questões por meio de análises de materiais teóricos da área e descobertas feitas ao longo do tempo sobre o tema. Apresentamos uma síntese do material coletado sobre um olhar crítico acerca das indagações constatadas por muitos estudiosos do tema e fizemos uma análise, que ajuda a compreender a nova tendência desta área, a preocupação com a sociedade.

Palavras-chave: marketing e ética; ética; propaganda e ética.

\section{Apresentação}

"Que oportunidade tem a ética no mundo globalizado de consumidores?"(BAUMAN, 2011, pág. 37).

Diante do acirrado cenário empresarial, em que há uma busca incansável pelo consumidor

\section{Abstract}

Within the area of marketing, there are many questions about ethics in marketing. But is it really it is present in this context? This research sought to answer this and others issues through analysis of a theoretical material and discoveries made on time about the subject. We also provide a summary of the material collected on a critical view of the questions found by many academics of the subject. Finally we did an analysis that helps to understand the new trend in this area, the concern for society.

Keywords: marketing and ethics; ethics; advertising and ethics.

final em todas as esferas de serviços oferecidos, podemos dar maior destaque ao mercado comercial, que atua, principalmente no Brasil, o Varejo. Tal segmento pode ser ressaltado, ainda, pela constante presença em todas as áreas da mídia, o que nos faz voltar atenção especial para o tipo de Marketing envolvido com os negócios.

\footnotetext{
${ }^{1}$ Mirelle Monique de Oliveira Fernandes - Pesquisadora da PUC/SP

2 Paulo Roberto Alves - Mestre Prof. pesquisador da PUC/SP e Prof Pesquisador da FICS onde desde o primeiro semestre de 2012 compõe a grupo de pesquisa - oficina de artigos e Iniciação Científica das Faculdades Integradas Campos Salles - FICS. www.campossalles.edu.br
}

${ }^{3}$ William Roberto Dondas - Pesquisador da PUC/SP 
Adentrando neste meio, e buscando compreender as ações especificamente da área de divulgação e promoção, surge um cenário econômico e social que merece atenção especial.

Necessitando trabalhar e desenvolver estratégias que atinjam o consumidor final, o intuito do Marketing, das propagandas e promoções realizadas pela área é, justamente, conseguir atrair consumidores. Até aqui, nada parece estar errado. Porém, na prática, inúmeras vezes deparamo-nos com algumas situações em que o setor comercial não atua de forma leal com seus clientes. Em um contexto como este, em 1991, quando estava no poder da República o Presidente Fernando Collor de Mello, foi implantado, no Brasil, o Código de Defesa do Consumidor (CDC). A partir de então, as atividades desenvolvidas na área comercial, especificamente na área do Marketing Empresarial, começaram a ser cuidadosamente planejadas, pois se entende que qualquer ação que infrinja as leis postas no CDC, pode levar as empresas a disputas judiciais.

Exatamente neste ponto surge a problemática: será que as empresas realmente atuam de forma ética? Será que os direitos do consumidor sempre são preservados e respeitados?

Acreditamos nas hipóteses de que em certos momentos de sua história, o Marketing pode ter agregado alguns valores éticos em suas práticas, os quais podem variar de acordo com o contexto histórico. Porém, com o surgimento de fortes valores capitalistas, o "ter" passou a predominar nas ações de Marketing, resultando em ações que podem ser prejudiciais aos consumidores (PASSOS, 2011).

Procurando respostas para estas questões, realizamos uma pesquisa inicialmente bibliográfica que se desdobrou em uma pesquisa descritiva do tema, culminando no presente artigo, seguida de reflexões, que apontaram o real caminho perseguido pelo
Marketing. Desenvolvemos um estudo sobre essa área para entender seu funcionamento e buscamos suas relações com a moral e a ética envolvidas no tratamento dos consumidores para tentar entender e explicar como são tratados os princípios éticos dentro do Marketing.

\section{O Marketing}

Em 1953, segundo NORMANHA FILHO (2004), o Marketing começou a ser ensinado nas Universidades Brasileiras, inicialmente na Escola de Administração de Empresas da Fundação Getúlio Vargas, em São Paulo. No exterior, teve início antes desta data. A partir de então, as discussões e os estudos referentes a esta área passaram a ser frequentes, como ainda hoje se fazem necessários. Muitos estudiosos buscaram definições desta prática que abarcassem a sua importância e alcance frente aos aspectos que envolvem o tratamento das informações para que se possam desenvolver as áreas que o Marketing visa atender, como ferramenta empresarial de grande valor (NORMANHA FILHO, 2004).

Segundo LAMB (2004, pág. 6), Marketing é "o processo de planejamento e execução da concepção, do preço, promoção, e distribuição de ideias, mercadorias, e serviços para criar trocas que satisfaçam os objetivos individuais e das organizações". Sendo assim, o Marketing não se resume a atividades relacionadas com promoção, pontos de venda, e fidelização de clientes, e outros. A troca também é um conceito fundamental, pois significa que todo o processo engendrado para apresentar os produtos aos clientes, realmente foi realizado da melhor maneira. Entretanto, o oposto não é verdadeiro, as pessoas, em sua maioria, realizam trocas por necessidade, não por simplesmente serem influenciadas a adquirir determinado produto.

Para o desenvolvimento das atividades de Marketing, são adotadas quatro filosofias. A primeira, uma orientação para a produção, tem 
um foco voltado mais para as capacidades internas das empresas do que para as necessidades dos clientes (LAMB, 2004).

Já a orientação para vendas, define que as pessoas comprarão mais produtos se forem adotadas técnicas agressivas neste ponto. E, a orientação para o mercado define que as vendas não ocorrem somente pelo fato da força empregada nas vendas, mas depende do processo de decisão do comprador. Assim, as empresas devem compreender que o cliente é quem define o valor daquilo que está comprando, e não elas mesmas. Por fim, a orientação para a sociedade, define que a organização não pode disponibilizar para seus clientes um produto que seja prejudicial para as pessoas. Por mais que o mercado seja competitivo, as empresas devem competir de maneira ética (LAMB, 2004).

De acordo com LAMB (2004, p.57), "ética comercial consiste, na realidade, em um subconjunto de importantes valores de vida aprendidos desde o nascimento. Os valores que os executivos usam para tomar decisões foram adquiridos por meio da família e das instituições educacionais e religiosas".

D'ANGELO (2003) diz que as ações realizadas no contexto do Marketing sempre foram alvo de questionamentos éticos, uma vez que é a atividade empresarial que tem mais visibilidade. Existem basicamente dois tipos de questionamentos éticos. O primeiro diz respeito ao estímulo materialista despertado pelo Marketing. O segundo enfoca atividades de Marketing, como precificação, propaganda e vendas.

Mesmo que as definições formais de Marketing alarguem sua abrangência, popularmente, o Marketing é confundido com propaganda pura e simples (D'ANGELO, 2003).

Um exame de algumas das atividades de Marketing é suficiente para perceber a frequência com que os profissionais da área se deparam com questões éticas. Praticamente todas as atividades de Marketing podem ser interpretadas de acordo com uma visão positiva ou negativa quanto a sua correlação ética. Nesse contexto, a experiência tende a conferir aos atores do mercado a capacidade de desenvolver mecanismos que lhes garantam alguma segurança. Não se sugere que as práticas dos negócios são antiéticas, mas que a maneira como os profissionais percebem seus papéis podem colocar em risco a ética de suas ações (D'ANGELO, 2003).

Percebemos que o Marketing é uma área permeada por questões éticas, e são de grande importância, pois é a atividade que tem o papel de aproximar a empresa de seus clientes. Sendo assim, os profissionais de Marketing necessitam usar todos os métodos de que dispõem, para realizar seu trabalho da melhor maneira possível (NORMANHA FILHO, 2004). É nesse momento que começam a aparecer os dilemas éticos. Até que ponto um profissional deve ir para que possa realizar o seu trabalho? Qual é o limite ético para as ações de um profissional de Marketing?

Esses questionamentos levam a inúmeras discussões, já que a ética não tem um conceito igual para todas as pessoas. Pode-se dizer que todos tentam agir dentro da ética de sua sociedade, mas por haver diferentes visões sobre o que é ético ou não, é difícil que se chegue a um consenso total sobre quais ações estão ou não dentro da ética (D'ANGELO, 2003).

\section{A Ética}

Como indica VALLS (2006), ética pode ser um estudo ou uma reflexão, científica, filosófica, ou até teológica sobre os costumes ou sobre as ações humanas, e pode ser também a realização de um tipo de comportamento. A ética está presente, no seu sentido geral, em todas as sociedades, em todos os momentos históricos e sempre está em constante mudança. As vivências diárias proporcionam mudanças de percepções, que interferem nos julgamentos que as pessoas fazem das coisas, 
das ações, e até das visões das pessoas ao seu redor, da sociedade onde vivem.

Percebemos, então, que as ideias sobre o que é ética podem ser diferentes de acordo com a época ou sociedade analisada. Porém, em todas as situações, encontramos a presença do bem e do mal. Agir com ética é agir de acordo com o bem.

A maneira como se entende o que é o bem pode variar, de acordo com o contexto analisado, mas a ideia de bem está presente em todas as formas de pensar éticas. (VALLS, 2006).

Atualmente, nossa sociedade vive uma época de reivindicação, em que os seres humanos buscam seu reconhecimento como tal, perante a sociedade, que os menospreza e impõe situações de opressão e de manipulação. As pessoas querem ser entendidas, compreendidas e aceitas por inteiro; não desejam ser, meramente, mais uma engrenagem deste sistema capitalista. Presenciamos uma mudança de paradigmas em curso na sociedade (PASSOS, 2011).

Neste sentido, surgem novos padrões, novas maneiras de pensar, de definir, de viver de forma ética dentro de nossa sociedade. No momento em que se torna difícil a aceitação das normas, das leis, e até das regras sociais de forma pacífica, é latente a busca dos indivíduos por serem reconhecidos como um todo, não só como aqueles nos quais se inculca padrões que devem ser aceitos e seguidos, mas como aqueles que conhecem seus direitos e têm poder e voz para defendê-los (PASSOS, 2011).

Para tanto precisamos ter ciência de que moral e ética caminham lado a lado. Possuem origens diferentes, mas significam o mesmo: um modo de agir, um costume adotado (PASSOS, 2011). Mas, são, no entanto, distintas também. Podemos dizer que a moral confere certa normatização e direção às ações das pessoas, enquanto a ética seria destinada ao estudo dessas práticas, dessas ações. Logo, "a Ética é a ciência da moral" (PASSOS, 2011, p.23). O alcance das práticas morais, entretanto só pode ser feito pelos seres humanos, pois este é responsável por suas ações; seus atos decorrem livre e conscientemente (PASSOS, 2011).

O ser humano é livre para fazer suas escolhas e deve se responsabilizar por elas. Porém, o momento histórico, as heranças de outras gerações, os condicionamentos a que são expostos, também ajudam a definir sua maneira de agir, suas práticas morais. Ele é o único que pode transformar a realidade a seu favor. É livre para isto e essa liberdade também depende do momento histórico, quando o indivíduo transforma a realidade para suprir suas necessidades. Os valores morais são interiorizados e pregados sutilmente. As crianças são "moldadas" por seus pais, sua família, sua escola etc.. Nesse sentido, os valores morais que predominam cristalizam-se pela experiência do grupo, da sociedade, pelos momentos de vida compartilhados em determinado momento. (PASSOS, 2011).

A prática moral em nossa sociedade é pautada pelo culto do eu, do uso das pessoas em benefício do sistema. Como todos nós conhecemos, nossa sociedade vive a era do "ter" que oprime o "ser", assim as relações interiores são totalmente oprimidas e desconsideradas (PASSOS, 2011). "Dentro dessa realidade, a concepção moral também se orienta na exploração do ser humano pelo ser humano: o egoísmo, a hipocrisia, o lucro e o individualismo são incentivados e até cultuados" (PASSOS, 2011, pág. 26).

Entretanto, pode haver uma "luz no fim do túnel". Uma mudança, neste cenário da prática moral existente, necessita de reflexões profundas, principalmente na esfera política (PASSOS, 2011). É necessário que haja mudanças de valores no que tange a consciência coletiva, já que se trata de uma mudança que afeta toda a sociedade, e não apenas o indivíduo. Uma nova ordem moral, acompanhada de novos valores, sugere que 
haja respeito à liberdade e à pluralidade de valores (PASSOS, 2011). Somente quando o ser humano for livre para escolher, quando deixar de ser alienado, e for tratado como fim e não como meio, é que poderemos dizer que estabelecemos uma nova ordem moral. Isto quer dizer, "a substituição de critérios externos por internos, pela escolha responsável, que é, sem dúvida, o paradigma ético mais eficaz para se assegurar a convivência pacífica entre os individuos e reconhecer os contrários" (PASSOS, 2011, pág. 29). Podemos encontrar, mesmo diante de fortes valores capitalistas, um pensamento voltado para o lado espiritual, o surgimento de uma maneira não mais mecânica de viver e de "ter", mas sim, um respeito e uma crença de que é preciso "ser" feliz, ter relações sociais, descansar após uma longa jornada de trabalho e assim por diante. (PASSOS, 2011).

Para que uma moral agregue valores, representativos de todos os seres humanos e que respeite suas vidas em todas as esferas, nós devemos operar em uma sociedade conjunta, cooperativa e participativa em todos os setores. (PASSOS, 2011).

\section{1. Ética no Marketing}

\begin{abstract}
"Marketing e ética começam a caminhar juntas, de forma identificável e como abordagem de estudos a partir da Escola do Macromarketing, quando se iniciaram as pesquisas dos impactos das atividades de Marketing e das organizações na sociedade e vice-versa" (NORMANHA FILHO, 2004, pág. 8).
\end{abstract}

Assim, o Marketing influencia e é influenciado pelo meio externo. Trabalha em função deste e de suas mudanças, de forma que as mudanças ocorridas durante, e no tempo, afetam a maneira como são desenvolvidos os estudos e as práticas utilizadas pela área dentro das empresas, em virtude da necessidade de atrair o público, os clientes, as pessoas, e persuadi-las para que adquiram seus produtos (NORMANHA FILHO, 2004). Então, a ética, que está presente dentro das empresas, tem obrigações a cumprir perante a sociedade, não deve somente contribuir para a satisfação das necessidades, mas, fazê-la de forma ética. Este fazer ético é influenciado pelo que é considerado e validado como ético frente ao tratamento das informações que são externalizadas pelas empresas sobre seus produtos e que atingem os consumidores (NORMANHA FILHO, 2004).

Como foi exposto anteriormente, o Marketing é uma atividade de negócios que faz uso de muitas outras atividades, de ações, que possibilitam a realização da aproximação dos clientes com as empresas e, principalmente, com seus produtos. Quando se fala em ética no Marketing, o que nos surge imediatamente, são as propagandas, os pontos de venda, as promoções, a atividade da logística da empresa, enfim, todas aquelas partes do processo de realização do Marketing que dizem respeito ao contato com o cliente. Entretanto, pensar se o Marketing é uma atividade que se preocupa com a ética ou não, precisa ser atribuído não só as partes do negócio (Marketing), mas ao todo que faz o negócio existir. Logo, ética no Marketing abarca, também, todas as atividades que envolvem a área (NORMANHA FILHO, 2004).

Ora, se o Marketing é uma das muitas atividades envolvidas no cenário empresarial de todas as organizações, então ele está diretamente ligado aos negócios das empresas. A partir deste ponto podemos pressupor que a ética parte de dentro para fora das organizações, do tratamento, da cultura organizacional, da missão, dos valores que esta adota para si na constituição de seu objetivo de existência no mercado (NORMANHA FILHO, 2004).

ARRUDA (2002, pág.. 1-3) apud FILHO (2004, p.11) tratando da conduta empresarial e da ética diz que:

"[...] A instituição necessita definir como deseja desenvolver-se, de tal forma que a postura ética, a conduta moral, os seus valores e crenças 
essenciais se tornem parte da cultura da organização".

Desta forma, é obrigação das empresas, na sua constituição e formação, tomarem para si a preocupação com o tratamento leal aos seus clientes. Isso pode inicialmente, parecer uma utopia frente ao atual cenário de competitividade que se apresenta nos dias de hoje, conforme acompanhamos em jornais e revistas.

O consumidor adquire os produtos, num pensamento simplista, para satisfazer suas necessidades. O Marketing busca, na maioria dos casos, tornar necessário o que é supérfluo para vender suas ideias, seus produtos, gerar lucro para as empresas. Porém, um dos objetivos principais do Marketing é realizar trocas, ou seja, a empresa abriria mão de seu produto em troca de um valor monetário por ele. Parece muito simples esta ideia. Mas, na realidade, com o passar dos anos, a figura vem mudando e a importância da ética pode ser percebida junto com essas mudanças (NORMANHA FILHO, 2004).

Com tantas empresas no mercado, aquela que consegue se sobressair frente às demais, consegue seu "lugar ao sol", pelo menos, durante algum tempo. Aí está o problema, muitas vezes as empresas tomam partido de ações que burlam algumas regras sobre prestação de informações aos consumidores ou, tentam mascarar o que o produto realmente oferece para conseguir lucrar com sua venda.

DURANDIN (1997, pág.13) diz que: “A propaganda e a publicidade têm por objetivo modificar a conduta das pessoas por meio da persuasão, quer dizer, sem parecer obrigá-las".

As empresas tentam persuadir os consumidores de forma que não percebam que estão sendo manipulados de alguma forma. Assim, diretamente, elas não seriam as responsáveis pela desinformação de seus clientes na prática da disseminação de seus produtos.
$\mathrm{Na}$ realidade, tratando-se da posse de informações sobre determinado produto, o consumidor é sempre aquele que desconhece as reais qualidades de um produto que está prestes a adquirir. Ele é, sendo isso usado de má fé ou não, ingênuo frente aos donos do poder, os que divulgam o produto. Esta relação de poder entre consumidor e empresas é marcada pela forte detenção daquele pelas organizações. (DURANDIN, 1997).

Pesquisando sobre os direitos do consumidor, chegamos ao conhecimento de leis, que protegem os consumidores, quando são vítimas da má fé no uso das informações divulgadas na mídia.

\section{O Código Brasileiro de Defesa do Consumidor (CDC)}

Criado para proteger os direitos dos consumidores dentro do mercado de consumo, nivelando suas relações com os fornecedores, a leitura do CDC possibilitou a constatação e destaque de alguns dos principais pontos e leis que regem este Código, seguindo nossa linha de análise.

Observamos que o CDC (cap. II, p.66 e 67, 2007), surgiu para regulamentar as ações entre as partes envolvidas nos negócios, não para causar desavenças ou discordâncias no cenário comercial. Segundo algumas reflexões anteriores que fizemos sobre o que tange a vulnerabilidade do consumidor em relação aos fornecedores de bens e serviços, esta deve ser, segundo a citação das páginas acima, reconhecida e devem-se utilizar ações governamentais para a proteção do cliente, além de estudos que permitam avaliar a evolução do mercado consumidor.

Pensando na atuação, nas práticas dos fornecedores relacionadas à promoção de seus produtos, o CDC nos diz o seguinte: 


\section{DAS PRÁTICAS COMERCIAIS}

Seção III - Da Publicidade

Art. 37. É proibida toda publicidade enganosa ou abusiva.

$\S 1^{\circ}$ É enganosa qualquer modalidade de informação ou comunicação de caráter publicitário, inteira ou parcialmente falsa, ou, por qualquer outro modo, mesmo por ocasião, capaz de induzir em erro o consumidor a respeito da natureza, características, qualidade, quantidade, propriedades, origem, preço e quaisquer outros dados sobre produtos e serviços.

$\S 2^{\circ}$ É abusiva, dentre outras, a publicidade discriminatória de qualquer natureza, a que incite à violência, explore o medo ou a superstição, se aproveite da deficiência de julgamento e experiência da criança, desrespeite valores ambientais, ou que seja capaz de induzir o consumidor a se comportar de forma prejudicial ou perigosa à sua saúde ou segurança.

$\S 3^{\circ}$ Para os efeitos deste Código, a publicidade é enganosa por omissão quando deixar de informar sobre dado essencial do produto ou serviço.

(CÓDIGO BRASILEIRO DE DEFESA DO CONSUMIDOR, p.336, 2007)

Logo, o CDC proíbe a utilização de publicidade enganosa ou abusiva perante os consumidores. Embora muitas vezes possamos nos deparar com algum tipo de irregularidade, essas são passíveis de pena segundo o CDC (2007, p.718 e 719). Nesse sentido, por que será que ainda há casos em que são constatadas essas irregularidades? De certo ponto de vista, tratando-se da justiça brasileira, podemos supor a facilidade que os fornecedores podem ter em lidar com as leis. Por outro lado, a falta de fiscalização, ou até mesmo a passividade do consumidor, podem acarretar estes vícios na área.

O CDC protege o consumidor das práticas abusivas dos fornecedores nivelando as relações fornecedor-consumidor, e pelas nossas pesquisas, como já tínhamos conhecimento prévio, podemos confirmar que, como todas as outras áreas e profissões, o Marketing possui códigos de ética profissional a serem seguidos. O AMA (Associação Americana de Marketing), abarca a ética que deve ser seguida no contexto global pelos profissionais da área, além de contar com acadêmicos do tema. No Brasil, o CONAR (Conselho Nacional de Auto-Regulamentação Publicitária), une os anunciantes e os profissionais de propaganda (O'BOYLE e DAWSON JR., 1992 apud D'ANGELO, p.56, 2003).

Esses Códigos visam regulamentar, direcionar as ações dos profissionais no cenário em que atuam, levando em consideração seu papel social, seu comportamento e trazendo normatização às suas atividades (D’ANGELO, 2003).

$\mathrm{O}$ conjunto formado pelo $\mathrm{CDC}$ e os Códigos de Ética dos profissionais de Marketing deveriam ser suficientes para que as relações consumidor-fornecedor ocorressem de forma harmoniosa. Entretanto, sempre observamos novas maneiras encontradas pelas empresas para "burlar" estas normatizações, frequentemente, nos comerciais da mídia televisiva.

\section{Novas perspectivas sobre o}

\section{Marketing}

O Marketing é uma das principais ferramentas da Administração de Empresas, e sua aplicação consiste basicamente, em processos de troca, com o objetivo de gerar lucro. Podemos perceber que hoje o Marketing não se resume apenas a isto. Percebemos uma mudança; o Marketing está assumindo suas responsabilidades econômicas, sociais e ambientais, isto é, está reconhecendo a necessidade que as empresas de hoje têm, em assumir suas responsabilidades dentro da sociedade (KOTLER, 2010).

Ao longo dos anos, o marketing evoluiu, passando por três fases, às quais chamamos de marketing 1.0, 2.0 e 3.0. Muitos profissionais de marketing de hoje continuam praticando o marketing 1.0, alguns praticam o marketing $2.0 \mathrm{e}$ outros ainda estão entrando na terceira fase, o marketing 3.0. As maiores oportunidades se abrirão aos profissionais que praticam o marketing 3.0. (KOTLER, 2010, p.3) da 
história do Marketing, podemos destacar diferentes fases na sua evolução.

No início, tínhamos o Marketing centrado no produto. Estes deveriam ser básicos e padronizados, com o intuito de reduzir ao máximo os custos de produção. Desse modo, o preço seria mais baixo e um maior número de pessoas poderiam adquirí-los. Não havia muita opção à disposição dos consumidores, e com produtos muito semelhantes, a melhor maneira de ganhar clientes era o preço baixo (KOTLER, 2010).

A segunda fase do Marketing é a fase atua modificando o foco do produto para o consumidor. $\mathrm{O}$ que o consumidor quer? Atender os desejos e necessidades dos consumidores se tornou a nova tarefa, e considerando que o consumidor de hoje tem acesso as mais diversas informações, e pode comparar produtos com facilidade, não é uma tarefa fácil (KOTLER, 2010).

Fidelizar consumidores exige muita criatividade dos profissionais de Marketing, que tentam, das mais variadas maneiras, chegar à "mente" do consumidor, descobrir o que ele quer, o que precisa, e assim satisfazê1o. (KOTLER, 2010)

A nova fase do Marketing, a qual KOTLER chamou de Marketing 3.0, surge em decorrência dos grandes avanços tecnológicos recentes, que chamamos de "nova onda de tecnologia". Essa tecnologia permite que indivíduos criem e consumam suas próprias notícias. Dessa forma, os consumidores tornam-se participativos, tendo poder de exercer influência sobre outros consumidores (KOTLER, 2010).

Um bom exemplo dessa nova tecnologia são as mídias sociais (Blogs, Facebook, Twitter, etc.). A maioria dos Blogs, ou comentários no Twitter é pessoal. As pessoas compartilham suas ideias e opiniões umas com as outras, sobre qualquer tipo de assunto.

Se por acaso uma pessoa faz um comentário ruim sobre um produto ou serviço, ela pode influenciar seus leitores a pensar da mesma maneira. À medida que as mídias sociais se tornarem mais expressivas - um maior número de consumidores poderá influenciar outros consumidores com suas opiniões (KOTLER, 2010).

Em suma, a era do marketing 3.0 é aquela em
que as práticas de marketing são muito
influenciadas pelas mudanças no comportamento
e nas atitudes do consumidor. É a forma mais
sofisticada da era centrada no consumidor, em
que o consumidor demanda abordagens de
marketing mais colaborativas, culturais e
espirituais. (KOTLER, 2010, pág..22)

O “Marketing 3.0" também é um Marketing voltado para o consumidor. No entanto, as empresas que o praticam, julgam que elas têm mais a oferecer à sociedade do que seus produtos e serviços. O objetivo é oferecer soluções para os problemas. A empresa enxerga e assume suas responsabilidades sociais, econômicas e ambientais, acredita que os consumidores são seres humanos completos (KOTLER, 2010).

Em tempos difíceis, como a recente crise econômica global, a sociedade enfrenta os mais diversos tipos de problemas, e as empresas não devem se preocupar apenas em como a crise as afetou, mas devem se preocupar em como a sociedade inteira foi afetada, e oferecer soluções a esses problemas. No "Marketing 3.0" as empresas se destacam por seus valores, que se apresentam de maneira diferenciada, comparados com os anteriores (KOTLER, 2010).

\section{Considerações Finais}

Considerando-se a amplitude que nosso problema de pesquisa poderia ter tomado e, sabendo da complexidade envolvida neste contexto, uma vez que envolve um dos conceitos essenciais da sociedade em geral: a ética, encontramos considerações plausíveis ao nosso objetivo.

É evidente que necessitamos dos serviços das empresas e que precisamos estar cientes 
dos produtos que elas podem nos oferecer e que julgam resolver nossos problemas, satisfazer nossas vontades. Porém, se antes as empresas eram preocupadas em apenas vender seus produtos, inculcando nos clientes, às vezes, ideias inverídicas, hoje, por decorrência das leis ou não, a prática está mudando o cenário.

Constatamos uma evolução dentro do Marketing que tem muito a oferecer para toda a sociedade e, as empresas que estiverem dispostas a adequar-se aos novos padrões de exigência dos consumidores da "Era TIC", com certeza só terão a ganhar financeiramente e serão registradas na área das mais confiáveis e leais pelos seus clientes. O Marketing está caminhando para uma nova perspectiva. As pessoas não são mais vistas como clientes, a empresa não busca apenas a satisfação funcional do cliente. $\mathrm{O}$ cliente agora é visto como um ser humano completo, e cabe à empresa trazer satisfação emocional e espiritual nos produtos e serviços que oferecem.

Em um cenário onde a participação dos clientes se tornou uma peça-chave, a empresa se destaca por seus valores, e deve ter como seu maior objetivo, estar preparada para apresentar soluções para os problemas enfrentados pela sociedade.

Encerrou-se a época em que apenas as trocas de uns produtos por outros já era o suficiente para satisfazer as expectativas das pessoas, em geral. Agora, não basta oferecer somente o que as pessoas precisam. Conhecer os desejos os anseios, as reais necessidades de cada cliente é a peça-chave para o sucesso de qualquer negócio.

Os consumidores estão cada vez mais perceptíveis às novas tendências, às ações mercadológicas e às divulgações que as empresas fazem na mídia. Ludibriar o cliente, como algumas antes acreditavam ser possível e julgavam ser fundamental para a promoção e venda dos produtos, já não é mais possível. As pessoas conhecem e buscam seus direitos, sabem das possíveis penalidades para as ações ilícitas das empresas. Elas têm poder para alavancar ou destruir uma empresa na palma de suas mãos, em suas próprias casas: as mídias sociais!

Então, como tudo na vida é fluido, com o Marketing com certeza não poderia ser de outra maneira. $\mathrm{O}$ fato é que as coisas poderiam evoluir de duas maneiras: positivamente ou negativamente, dependendo do contexto e das reais necessidades. Felizmente, o Marketing vem demonstrando uma evolução positiva e inovadora. Ter a capacidade de perceber as constantes mudanças no macroambiente e adaptar-se a elas é uma exigência para as empresas que desejam perenidade em seus negócios e sucesso em curto e longo prazo.

\section{Referências Bibliográficas}

ARANTES, M. M. OLIVEIRA, R. S. de. Revista Administração em Diálogo. Disponível em: <revistas.pucsp.br/index.php/rad/article/download/2126/1279>. Acesso em: 09 out. 2011.

BAUMAN, Z. A ética é possível num mundo de consumidores? Tradução Alexandre Werneck. Rio de Janeiro: Ed. Zahar, 2011.

COSTA, R.; FRAGA, J.; JIMENES, R.. Revista da Faculdade de Direito. Disponível em: < https:// www.metodista.br/revistas/revistas-ims/index.php/RFD/article/view/522/520>. Acesso em: 11 out. 2011. 
D’ANGELO, A. C. Revista de Administração Contemporânea. Curitiba, out. nov. 2003, vol.7 no. 4. Disponível em:<http://www.scielo.br/scielo.php?pid=S141565552003000400004 \&script $=$ sci_artt $>$. Acesso em: 21 mai. 2011.

DURANDIN, G. As mentiras na propaganda e na publicidade. São Paulo: JSN Editora, 1997. GRINOVER, A. P. et al. Código Brasileiro de Defesa do Consumidor: comentado pelos autores do anteprojeto. 9. ed. Rio do Janeiro: Forense Universitária, 2007.

KOTLER, P. Marketing para o Século XXI: como criar, conquistar e dominar mercados. São Paulo: Ediouro, 2009.

. Marketing 3.0: as forças que estão definindo o novo marketing centrado no ser humano. Rio de Janeiro: Elsevier, 2010.

LAMB, C. W.; HAIR JR., Joseph F.; MCDANIEL, C. Princípios de marketing. Tradução: Luciana Penteado Miquelino. Revisão técnica: Tânia Maria Vidigal. Limeira. São Paulo: Pioneira Thomson Learning, 2004.

LOUREIRO, O. I. Um estudo sobre as origens e evolução do marketing: a influência das correntes teóricas -americana e europeia- na docência da disciplina em instituições brasileiras de ensino superior. 2006. Dissertação (Mestrado em Administração) - Faculdade de Economia e Administração, Pontifícia Universidade Católica, São Paulo.

NORMANHA FILHO, M. A. Revista Brasileira de Gestão de Negócios. Disponível em: <http:// redalyc.uaemex.mx/pdf/947/94761502.pdf>. Acesso em: 11 out. 2011.

PASSOS, E. Ética nas organizações. 1. ed. São Paulo: Atlas, 2011.

VALLS, A. L. M. O que é ética. São Paulo: Brasiliense, 2006. 